\title{
Molecular Analysis of Polymorphisms in IL-6 Gene and the Predisposition to Osteoporosis Using Variable Number of Tandem Repeats-Polymerase Chain Reaction (VNTRS-PCR) Technique
}

\author{
Maysaa Abdul Razzaq Dhahii (Corresponding author) \\ Microbiology Department/College of Medicine, Al-Nahrain University \\ PO Box 70062, Al-Kadhmiya-Baghdad-Iraq \\ Tel. 964-7901-736-316 E-mail: dr_maysaa@yahoo.com \\ Shymaa Jamal Al-Anee \\ Medical Biology Department/ College of Medicine, Baghdad University \\ Bab-Almuadam,Baghdad,Iraq \\ Tel: 964-7901-776-223_E-mail: shaymajamal@yahoo.com
}

Sadeic Auaid. Ali

Rheumatology Department/ Al-Kademyia teaching hospitals

Al-Kadhmiya-Baghdad-Iraq

Tel: 964-7904-298-541_E-mail: ph.wamed@yahoo.com

Ahmed Samir Al-Naaimi

Community Medicine Department/ College of Medicine, Baghdad University

Bab-Almuadam, Baghdad, Iraq

Tel: 964-7901-748-475_E-mail: ahmed_ihss2@yahoo.com

Received: December 06, 2010 Accepted: December 22, 2010 doi:10.5539/ijb.v3n2p82

\begin{abstract}
Osteoporosis (OP) is considered to be a multifactorial syndrome with environmental and genetic factors interacting to determine bone mass. IL6 is a pleiotropic cytokine that has multiple effects on different cell types. It is stimulates osteoclast development, therefore, it has been implicated in osteoporosis. In this study, 26 patients that diagnosed clinically as osteoporosis were enrolled at Al-Kademyia teaching hospital -Ministry of health from April 2009 to February 2010.

Also, 30 blood samples from 30 healthy individuals, considered as negative control, were screened. One ml of venous blood (VB) sample was obtained from each subject. DNA was extracted from VB using DNA isolation kit. The 3' flanking region of the IL-6 gene was amplified using a variable number tandem repeats-polymerase chain reaction (VNTRs-PCR). PCR products were electrophoresed using 3\% agarose gel electrophoresis.

Analysis of genotypes in the 56 individuals studied shows evidence of 4 length variants with product sizes ranging approximately between $(610-695) \mathrm{bp}$. The analysis showed that $24(92 \%)$ of patients were carried risk genotypes, while (7\%) were carried non-risk genotypes. All negative controls were carried non-risk genotypes.

Investigating whether an individual possesses a risk genotype of an IL-6 gene, a gene that correlates with predisposition to osteoporosis by screening if this patient homozygous or heterozygous for IL-6 gene using VNTRs-PCR considered as a simple and more specific analysis.
\end{abstract}

Keywords: Osteoporosis, Genotyping, IL-6 


\section{Introduction}

Osteoporosis (OP) is a condition of skeletal fragility characterized by low bone mass and by microarchitectural deterioration of bone tissue, with a consequent increase in risk of fracture. It is one of the most prevalent of age-related diseases (Stewart \& Ralston, 2000). The process of bone loss is particularly acute in women because they have smaller, less- dense bones than do men. Their rate of bone loss sharply increases in the five years following menopause, when their ovaries stop producing estrogen. The process of bone loss is gradual. Most cases of osteoporosis remain undetected until an individual appears in the emergency department with fractures, which, in patients suffering from osteoporosis, usually occur in the hip, wrist, or spine. While osteoporosis is well known as a condition affecting post-menopausal women, significant numbers of men are also affected by the disease. Each year approximately one third of hip fractures occur in men (Beraducci, 2004; Whitehead,2004).

Polymorphisms in the promoter region of the IL-6 gene may result in inter-individual variation in transcription and expression. Genetic variants could therefore influence an individual's susceptibility to a diverse range of diseases(Huang \& Kung, 2006).

A number of recent studies investigated the clinical impact of the IL-6 polymorphisms on different major diseases such as chronic obstructive pulmonary disease, viral infections, gout, osteoporosis and diabetes(He et al., 2009; Gadelha et al., 2008; Tsai et al., 2008; Magana et al.,2008 \& Koh et al., 2009).

The human interleukin-6 (IL6) gene is located at chromosome 7p15-p21. At least four alleles are observed in the 3 ' flanking region of the gene (Stewart \& Ralston, 2000). Many highly informative DNA polymorphisms are due to insertion/deletion events, such as those due to variable numbers of tandem repeats (VNTRs). The detection of length polymorphisms by PCR followed by agarose gel electrophoresis to resolve the length of the products, would considerably simplify the analysis of individuals having a predisposition or susceptibility to certain disease states, in particular, osteoporosis (Dinçel et al., 2008). It is a further object of the invention to identify individuals having such a predisposition or susceptibility by determining a relevant genotype of an individual.

\section{Research Methods}

\subsection{Patients}

In this study, 26 patients that diagnosed clinically as osteoporosis were enrolled at Al-Kademyia teaching hospital -Ministry of health from April 2009 to February 2010.

Factors described cases with OP include: age, gender, weight, menopausal stat, time from cutting menopausal were shown in Table 1. Also, 30 blood samples from 30 healthy individuals considered as negative control were screened clinically. All subjects were randomly selected concerning to these factors. Individuals with secondary causes of osteoporosis (corticosteroid use, pituitary disease, primary hyperparathyroidism, neoplasia and thyrotoxicosis) were excluded.

One $\mathrm{ml}$ of venous blood (VB) sample was obtained from each subject, placed in tube containing EDTA (as anti-coagulant) and kept at $-20^{\circ} \mathrm{C}$ until used.

\subsection{DNA extraction}

DNA was extracted from $300 \mu 1$ venous blood (VB) using DNA isolation kit (Promega, USA) following manufacturer information. DNA concentration and purity were estimated according to Sambrook et al. (Sambrook et al.,1989) using ultra violate spectrophotometer (CECIL, CE 7200).

\subsection{VNTRS-PCR}

The 3' flank of the IL-6 gene was amplified using a variable number tandem repeat polymorphism-polymerase chain reaction (VNTR-PCR) according to Bowcock et al. (Bowcock et al. 1989). Briefly, master mix was prepared as following (per one reaction): $10 \mu \mathrm{l}$ of $5 \mathrm{X}$ PCR buffer, $0.5 \mu \mathrm{l}$ of $200 \mu \mathrm{m}$ dNTPs(Promega, USA), $2.2 \mu 1$ (equivalent to $25 \mathrm{pmol}$ ) of forward primer:

5 GCAACTTTGAGTGTGTCACG 3', and $2.5 \mu \mathrm{l}$ (equivalent to25 pmol) of reveres primer: 5 TGACGTGATGGATGCAACAC 3', 2.5 Units of Green Go Taq DNA polymerase (Promega, USA) and the volume was completed to $48 \mu \mathrm{l}$ using $\mathrm{dH} 2 \mathrm{O}$. Two micro liters (equivalent to 100ng) of patient's diluted DNA was added to master mix reaction. Also, negative controls reaction tubes were prepared, one reaction tube contain DNA extracted from healthy individual and one no-template control (NTC) reaction tube containing $\mathrm{dH}_{2} \mathrm{O}$.

The PCR reaction tubes were transferred into the thermocycler (eppendroff-thermal cycler, Germany), that were programmed as following: $94^{\circ} \mathrm{C}$ for $1 \mathrm{~min}(1 \mathrm{X}),\left\{92^{\circ} \mathrm{C}\right.$ for $2 \mathrm{~min}, 64^{\circ} \mathrm{C}$ for $1 \mathrm{~min}$ and $72^{\circ} \mathrm{C}$ for $\left.1 \min \right\} \mathrm{X} 30$, 
$72^{\circ} \mathrm{C}$ for $10 \mathrm{~min}(1 \mathrm{X})$. Then, PCR products were electrophoresed using $3 \%$ agarose gel electrophoresis at $3 \mathrm{~V} / \mathrm{cm}$ for $90 \mathrm{~min}$.

PCR products of size about 675 bp and about 695 bp indicate a non-risk genotype of an IL-6 gene (Bowcock et $a 1 ., 1989$ ). Hence, the non-risk genotype is a heterozygous genotype in which specific polymorphic variants (or alleles) of the IL- 6 gene are different on respective chromosomes. A risk genotype is (a) any homozygous IL-6 genotype or (b) a heterozygous genotype in which the PCR products are (i) not about 675 bp and (ii) not about $695 \mathrm{bp}(\mathrm{p} 2)$.

Figure (1) shows PCR amplification products from different subjects. The assay considered satisfactory for interpretation when no-template control reaction shown no amplified product.

Figure (1.1) shows the PCR products from fore patients showed evidence of 2 length variants with product sizes ranging (approximately) between 610bp-640bp.

Figure (1.2) shows the PCR products from six individuals homozygous for two different classes of alleles (approximately $610 \mathrm{bp}$ and $640 \mathrm{bp}$ ).

Figure (1.3) shows the PCR products from one patient (610/640 heterozygous to IL-6 gene) and one healthy individual (675/695 heterozygous to IL-6 gene).

\subsection{Statistical analysis}

Frequency distributions for selected variables were done first. The present study is a case control study, in which the calculated OR is the best estimate for the real measure of risk (RR) which can be calculated in cohort studies only. To measure the strength of association between 2 categorical variables, such as the presence of certain antigen and disease status the odds ratio (OR) was used. The statistical significance of the measured OR is assessed by a special $\chi 2$ formula.

\begin{tabular}{|c|c|c|c|c|c|}
\hline & & \multicolumn{2}{|c|}{ Disease status } & \multirow{4}{*}{\multicolumn{2}{|c|}{$O R=\frac{\frac{A}{B}}{\frac{C}{D}}=\frac{A D}{B C}$}} \\
\hline & & $\begin{array}{c}+ \\
(\mathrm{RA})\end{array}$ & $\begin{array}{c}- \\
\text { (Controls) }\end{array}$ & & \\
\hline \multirow{2}{*}{$\begin{array}{l}\text { Presence of specific } \\
\text { HLA-antigen }\end{array}$} & + & A & B & & \\
\hline & - & $\mathrm{C}$ & D & & \\
\hline \multirow{2}{*}{\multicolumn{2}{|c|}{$\chi^{2}=$}} & \multicolumn{2}{|c|}{1} & \multirow{2}{*}{$\times(\log$} & \multirow{2}{*}{$\left.e^{O R}\right)^{2}$} \\
\hline & & $\frac{\bar{A}}{A}+\frac{1}{B}$ & $\frac{1}{C}+$ & & \\
\hline
\end{tabular}

Since HLA-antigen system is a very heterogenous one, certain antigens may be lacking in cases or control group, which causes the value of OR to be zero or undetermined (division by zero). In such cases an approximation of OR may be calculated by a modified formula.

$$
\begin{gathered}
\text { OR }=\frac{A D}{B C}=\frac{(1+2 A) \times(1+2 D)}{(1+2 B) \times(1+2 C)} \\
\chi^{2}=\left(\frac{1}{\frac{1}{1+A}+\frac{1}{1+B}+\frac{1}{1+C}+\frac{1}{1+D}}\right) \times\left(\log e^{O R}\right)^{2}
\end{gathered}
$$

An estimate was considered statistically significant if its $P$ value was less than an $\alpha$ level of significance of 0.05 . The etiologic and preventive fraction are useful to assess how much of the risk of having the disease (or being free of the disease in case of preventive fraction) is attributable to the specific antigen under question and thus at the population level how much of the incidence of the disease can be decreased by controlling the risk factor (Emery, 1976). 


\section{$\mathrm{EF}=[(\mathrm{OR}-1) / \mathrm{OR}] \mathrm{X} \mathrm{Pc}$}

$$
\mathrm{PF}=[(1-\mathrm{OR}) \mathrm{X} \mathrm{Pc}] /[\mathrm{OR} \mathrm{X}(1-\mathrm{Pc})+\mathrm{Pc}]
$$

Were Pc $=$ Prevalence (relative frequency) of specific antigen among cases

$\mathrm{OR}=$ Odds ratio of having the disease in the presence of specific HLA antigen

\section{Results}

A total of 56 venous blood samples, 26 from patients diagnosed clinically as osteoporosis and 30 from healthy individuals were screened for determining the genotypes (homozygous or heterozygous) of the IL- 6 gene using VNTRs-PCR.

The overall mean age of patients was 55.1 years with a range of $50-70$ years. The overall mean age of healthy individuals included in this study as OP negative control were 58years, ranging from (45-65) years.

Of female included in this study, 30.7\%were pre-menopausal while $69.2 \%$ were post-menopausal. In the post-menopausal patients, the overall mean age of patients was 61years with a range of (52-70) years. The range of times elapsed since menopause varied from 6 ms- 18 years with a mean of 11.6 years.

History of fracture was seen in $6(23 \%)$ patients. Family history with OP was seen in $11(42.3 \%)$ patients.

Analysis of genotypes in the 56 individuals studied shows evidence of 4 length variants with product sizes ranging approximately between (610-695) bp. The analysis showed that $24(92 \%)$ of patients were carried risk genotypes, while $2(7 \%)$ were carried non-risk genotypes. All negative controls were carried non-risk genotypes, Table.2.

\section{Discussion}

A particular method of the invention comprises screening for a polymorphism in a TA repeat in the 3' flanking region of an IL-6 gene wherein polymorphisms are distinguished one from another by the respective sizes of products of PCR amplification. A set of PCR primers is used to amplify a part of the 3 ' flanking region of an IL-6 gene facilitate a rapid study of diseases associated with this gene.

Genetic markers for diagnosis that encodes calcium-regulating hormones, receptors and cytokines have been identified previously as potential osteoporosis markers (Mann, 2001; van Meurs, 2003).

From 26 patients studied, $92.3 \%$ were related to risk group, while $7.6 \%$ were related to non-risk group.According to World Health Organization (WHO) definition, $(22.5 \%)$ of the study groups were normal, (47\%) were osteoporotic osteoporosis (Bustamante et al., 2007). In this study, these proportions are expected in a predominantly postmenopausal cohort of women, since the prevalence of osteoporosis increases with age.

Even 24 patients were carried genetically predisposing factors of OP, but only $25 \%$ were have history of fracture (mostly in wrist and pelvis). This fact concerned with the result obtained by other study(Bustamante et al., 2007).

Moffett et al. (2004) analyzed the relationship between the IL-6 polymorphism in specific locus and osteoporosis associated with fracture in 3376 older women; they found that variation at specific IL-6 gene locus may contribute to genetic susceptibility to bone fragility.

In one study aimed to investigate the risk assessments of both patients with hip fractures and non-fractured by examining differences in the IL- 6 gene polymorphisms in Turkish population, they found that there was not significant relationship (Dinçel et al., 2008).

Family history of OP was seen in $45.8 \%$ of patients. This percentage may be dose not reflect the fact, because some patients had not idea about this subject.

It was referred to the evidence for genetic contribution to osteoporosis. A Study in twins and families indicate that genetic factors play an important role in the regulation of bone mineral density and other determinants of osteoporotic fracture risk (van Meurs et al., 2003).

As shown in table 2, the 610/610 genotype significantly increase the risk for having osteoporosis by 13.4 times, while $640 / 640$ genotype significantly increase the risk of having osteoporosis by 17.2 times. Being positive for $610 / 640$ genotype is associated with the highest risk of having osteoporosis, since it was associated with a statistically significant higher risk by 99.5 times compared to healthy controls. Being positive for $675 / 695$ genotype is highly protective against osteoporosis. The absence of this antigen is associated with a statistically 
significant increase in osteoporosis by a very high amount. Although the sample size for this study was small it was shown that the etiologic fraction for genotype $610 / 640$ is 0.619 , i.e. this genotype is expected to be responsible for $61.9 \%$ of osteoporosis cases at the population level.

The frequencies of the different classes of alleles differ in different human populations. The 610 class is most frequent in Caucasoids.. The other alleles are rarer, and alleles other than those of the760, 680, 640 and 610 classes have been seen most commonly in Africa(Dinçel et al., 2008).

Note: This work was done in Molecular Biology Lab-College of Medicine-Al Nahrain University.

\section{References}

Beraducci, A. (2004). Osteoporosis education: a health-promotion mandate for nurses. Orthopedic nursing, 23, 118-120.

Bowcock A., Rayl A., Erlich H. \& Sehgal P.B. (1989). Rapid detection and sequencing of alleles in the 3' flanking region of the interleukin-6 gene. Nucleic Acids Research, 17, 6855-6864.

Bustamante M., Nogués X., Mellibovsky L., Agueda L., Jurado S. \& Caceres E. (2007). Polymorphisms in the interleukin-6 receptor gene are associated with bone mineral density and body mass index in Spanish postmenopausal women. European J. of Endocrinology, 157, 677-684.

Dinçel E., Sepici-Dinçel A., Sepici V., Ozsoy H. \& Sepici B. (2008). Hip fracture risk and different gene polymorphisms in the Turkish population. Clinics, 63.

Emery A.E.H. (1976). Methodology in medical genetics: An introduction to statistical methods. First edition, Churchill Livingstone, UK. 98-102.

Gadelha S.R., Junior Alcantara L.C. \& Costa G.C. (2008). Correlation between polymorphisms at interleukin-6 but not at interleukin-10 promoter and the risk of human $\mathrm{T}$ lymphotropic virus type I-associated myelopathy/tropical spastic paraparesis in Brazilian individuals. Journal Medical Virology, 80, 2141-2146.

He J.Q., Foreman M.G., Shumansky K., Zhang X., Akhabir L., Sin D.D., Man S.F. \& Demeo D.L. (2009). Associations of IL6 polymorphisms with lung function decline and COPD. Thorax, 64,698-704.

Huang Q.Y. \& Kung A.W. (2006). Genetics of osteoporosis. Molecular Genetics and Metabolism, 88, 295-306.

Koh S.J., Jang Y. \& Hyun Y.J. (2009). Interleukin-6 (IL-6) -572C-->G promoter polymorphism is associated with type 2 diabetes risk in Koreans. Clin Endocrinol (Oxf), 70, 238-244.

Magana J.J., Gomez R., Cisneros B.,Casas I. \&Valdes M. (2008). Association of interleukin-6 gene polymorphisms with bone mineral density in Mexican women. Arch Med Res,39, 618-624.

Mann V. (2001). Acolla1 Sp1 binding site polymorphism predisposes to osteoporotic fracture by affecting bone density and quality . Journal of Clinical investigation, 107, 899-907.

Moffett S.P., Zmuda M.J. \& Cauley A.J. (2004). Association of the G-174C Variant in the Interleukin-6 Promoter Region with Bone Loss and Fracture Risk in Older Women. Journal of Bone Miner Res., 19, 1612-1618.

Sambrook J., Fritsoh E.F. \& Maniatis T. Molecular cloning: A laboratory manual. $2^{\text {nd }}$ edition. 1989.

Stewart T.L. \& Ralston S.H. (2000). Role of genetic factors in the pathogenesis of osteoporosis. Journal of Endocrino, 166, 235-245.

Tsai P.C., Chen C.J., Lai H.M. \& Chang S.J. (2008). Analysis of polymorphisms in the promoter region and protein levels of interleukin-6 gene among gout patients. Clin Exp Rheumatol, 26, 841-847.

van Meurs J.B.J., Schuit S.C.E. \& Weel A.E.A.M..(2003). Association of 5` estrogen receptor alpha gene polymorphisms with bone mineral density, vertebral bone area and fracture risk. Human Mol. Genetics, 12, 1745-1754.

Whitehead D. (2004). A preventative health education program for osteoporosis. Journal of advanced nursing, $47,15-24$. 
Table 1. Description of cases with Osteoporosis

\begin{tabular}{|c|c|c|c|}
\hline \multicolumn{2}{|c}{} & $\begin{array}{c}\text { Patients } \\
\text { no. }\end{array}$ & $(\%)$ \\
\hline \multirow{3}{*}{ Menopauses } & Post & 18 & 75.0 \\
\cline { 2 - 4 } & In & 4 & 16.7 \\
\cline { 2 - 4 } & No & 2 & 8.3 \\
\hline \multirow{3}{*}{ History of fracture } & Yes & 6 & 25.0 \\
\cline { 2 - 4 } & No & 18 & 75.0 \\
\hline \multirow{3}{*}{ Family history } & Yes & 7 & 45.8 \\
\cline { 2 - 4 } & No & 6 & 29.2 \\
\cline { 2 - 4 } & Unknown & 2 & 8.3 \\
\hline \multirow{2}{*}{ Hysterectomy } & Yes & 22 & 91.7 \\
\cline { 2 - 4 } & No & & \\
\hline
\end{tabular}

Table 2 Analysis of genotypes in the subjects included in the study

\begin{tabular}{|c|c|c|c|c|c|c|c|c|c|}
\hline & \multicolumn{2}{|c|}{ Case } & \multicolumn{2}{|c|}{ Control } & \multirow[b]{2}{*}{ OR } & \multirow{2}{*}{$\begin{array}{c}\text { Inverse } \\
\text { OR }\end{array}$} & \multirow[b]{2}{*}{$\mathrm{EF}$} & \multirow[b]{2}{*}{$\mathrm{PF}$} & \multirow{2}{*}{$\begin{array}{l}\text { P (Fisher's } \\
\quad \text { exact) }\end{array}$} \\
\hline & $\mathrm{N}$ & $\%$ & $\mathrm{~N}$ & $\%$ & & & & & \\
\hline \multicolumn{10}{|c|}{ Genotypes } \\
\hline $610 / 610$ & 4 & 16.7 & 0 & 0 & 13.4 & $* *$ & 0.155 & $* *$ & 0.034 \\
\hline $640 / 640$ & 5 & 20.8 & 0 & 0 & 17.2 & $* *$ & 0.196 & $* *$ & 0.013 \\
\hline $610 / 640$ & 15 & 62.5 & 0 & 0 & 99.5 & $* *$ & 0.619 & $* *$ & $<0.001$ \\
\hline $675 / 695$ & 0 & 0 & 30 & 100 & $<0.001$ & 2989 & $* *$ & $* *$ & $<0.001$ \\
\hline Total & 24 & 100 & 30 & 100 & & & & & \\
\hline
\end{tabular}

-OR : odds ratio, $\mathrm{N}$ : number. 


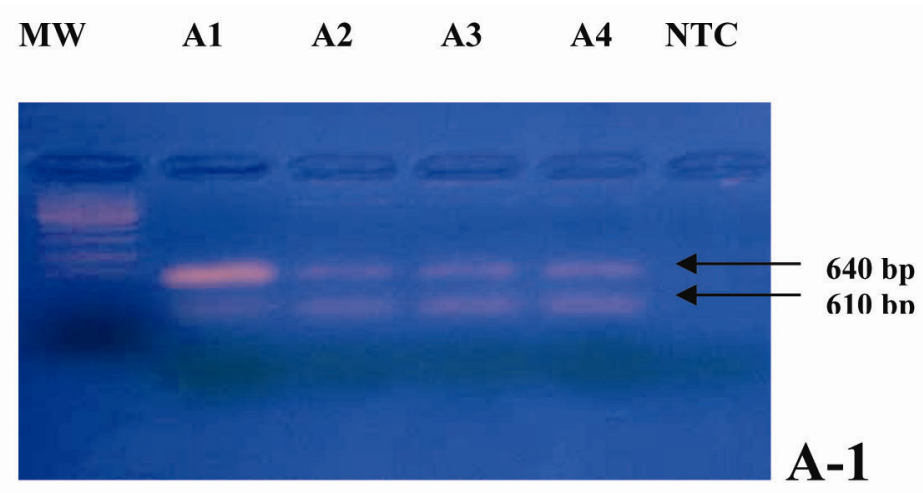

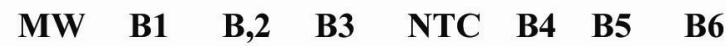
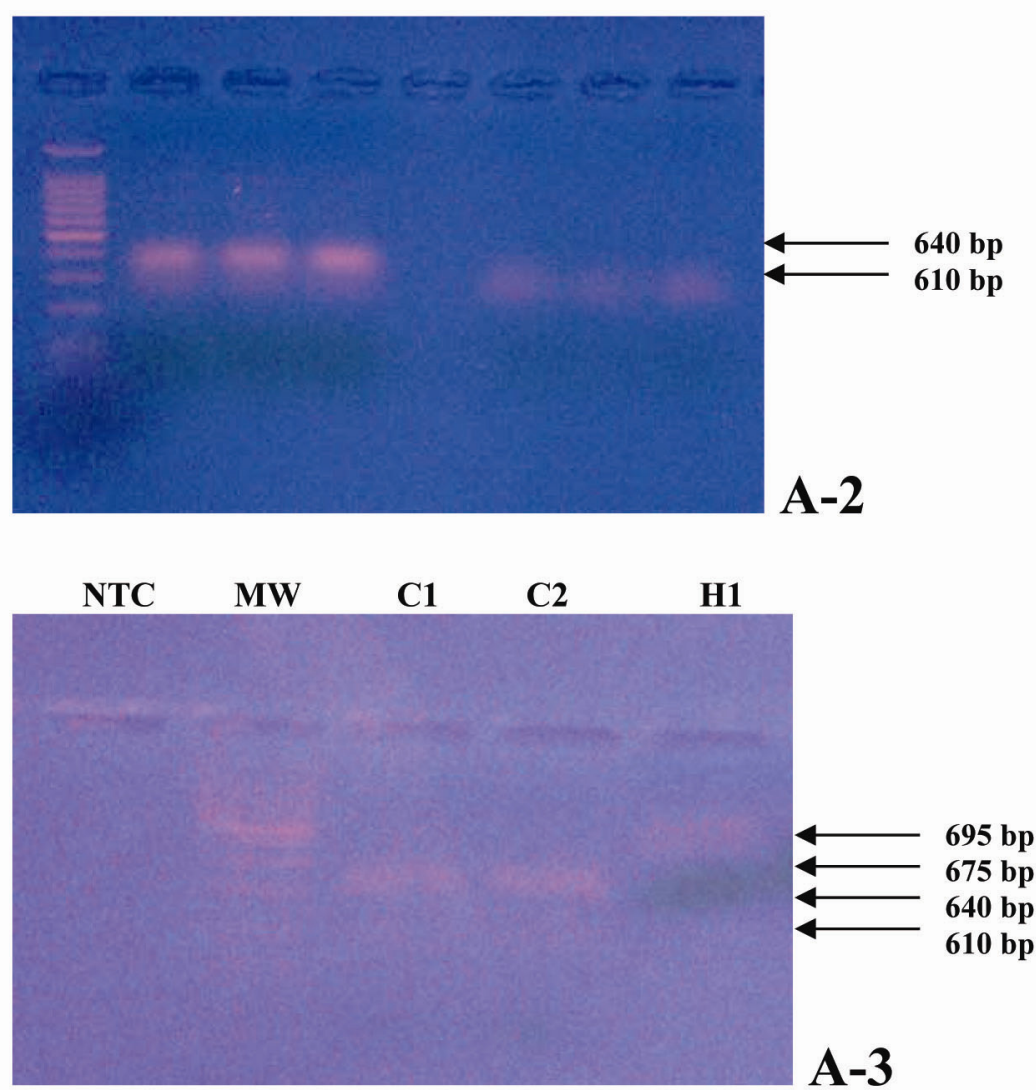

Figure 1. Genotypes analysis of $I L-6$ using VENTER. Lane (NTC): No template control. (M): Molecular weight marker of lambda DNA restricted with Eco RI+Hind III. Electrophoresis was carried out in 3\% agarose gel supplied with ethidiume bromide at $(3 \mathrm{~V} / \mathrm{cm})$ for 60 mints.

1.1 Lane (A1-A4) indicated amplified products of patients heterozygous for IL- 6 gene, allele class $610 \mathrm{bp} / 640$ bp.

1.2 Lane (B1-B6) indicated amplified products of patients homozygous for IL-6 gene allele class 610/610 bp and $640 / 640 \mathrm{bp}$.

1.3 Lane (C1 and C2) indicated PCR products from two patients (heterozygous to IL-6 gene, 610/640). Lane H1 indicated healthy individual (heterozygous to IL-6 gene, 675/695). 